\title{
PSICOLOGIA ESCOLAR: HUMANIZAR É PRECISO
}

\author{
PSICOLOGÍA ESCOLAR: LA HUMANIZACIÓN ES NECESARIA
}

SCHOOL PSYCHOLOGY: HUMANIZING IS NECESSARY

\author{
Jonas Lincoln MEDOLAGO ${ }^{1}$ \\ Tayná Maiara Pilla RODRIGUES ${ }^{2}$ \\ Maria Luiza MARIANO ${ }^{3}$
}

RESUMO: O presente artigo aborda uma experiência de intervenção no campo da Psicologia Escolar em uma Escola Municipal, realizado por um acadêmico do curso de graduação em Psicologia da Faculdade Anhanguera de Bauru, no segundo semestre de 2019. A realização do estágio escolar possibilitou não apenas a vivência da prática, mas um maior conhecimento de uma das áreas de atuação da Psicologia, a Psicologia Escolar, uma área ainda nova, em que há uma necessidade de profissionais interessados e a consequente carência destes no ambiente escolar. $\mathrm{O}$ processo de ensino-aprendizagem está atrelado não apenas à formação técnica, metodológica, mas também a sua formação humana. Para o levantamento dos dados foram aplicados dois questionários, os professores responderam de acordo com a vivência em sala de aula, levando como relevância a metodologia, didática e habilidades sociais. Nos resultados obtidos, a maior parte dos Professores tem dificuldades na relação "Professor/Aluno", foi possível embasar uma intervenção para que a aprendizagem ocorra de uma forma mais humana, estreitando o vínculo entre professor e aluno para a construção do conhecimento, juntamente com todos os atores da escola.

PALAVRAS-CHAVE: Artigo. Humanização. Psicologia escolar.

RESUMEN: Este artículo analiza una experiencia de intervención en el campo de la Psicología Escolar en una Escuela Municipal, realizada por un académico del curso de grado en Psicología del Colegio Anhanguera de Bauru, en el segundo semestre de 2019. La realización de las prácticas escolares permitió no sólo la experiencia de la práctica, sino un mayor conocimiento de una de las áreas de psicología, Psicología Escolar, una nueva área, donde hay una necesidad de profesionales interesados y la consiguiente falta de éstas en el entorno escolar. El proceso de enseñanza-aprendizaje está vinculado no sólo a la formación técnica y metodológica, sino también a la formación humana. Para la recopilación de datos, se aplicaron dos cuestionarios, en los que los profesores respondieron de acuerdo a su experiencia en el aula, tomando como relevancia la metodología, didáctica y habilidades sociales. En los resultados obtenidos, la mayoría de los profesores tienen dificultades en la

1 Faculdade Anhanguera de Bauru (FAB), Bauru - SP - Brasil. Graduando em Psicologia. ORCID: https://orcid.org/0000-0002-0380-1175. E-mail: lincoln.jlmm@gmail.com

${ }^{2}$ Faculdade Anhanguera de Bauru (FAB), Bauru - SP - Brasil. Docente Assistencial Preceptora em Psicologia. ORCID: https://orcid.org/0000-0002-2119-5068. E-mail: taynapilla@gmail.com

${ }^{3}$ Faculdade Anhanguera de Bauru (FAB), Bauru - SP - Brasil. Docente do Departamento de Psicologia e Pedagogia. Mestre em Psicologia do Desenvolvimento e Aprendizagem (UNESP). ORCID: https://orcid.org/00000002-9148-2732. E-mail: luizamariano@yahoo.com.br 
relación "Maestro/Estudiante", fue posible apoyar una intervención para que el aprendizaje se produzca de una manera más humana, fortaleciendo el vínculo entre profesor y alumno para la construcción del conocimiento, junto con todos los actores de la escuela.

PALABRAS CLAVE: Artículo. Humanización. Psicología escolar.

ABSTRACT: This article deals with an intervention experience in the field of School Psychology in a Municipal School, conducted by an undergraduate Psychology student at Anhanguera College of Bauru, in the second semester of 2019. The accomplishment of the school internship made possible not only the experience of practice, but a greater knowledge of one of the areas of activity of Psychology, School Psychology, an area still new, where there is a need for interested professionals and the consequent lack of them in the school environment. The teaching-learning process is linked not only to technical, methodological, but also human formation. For the data survey two questionnaires were applied, where teachers answered according to the experience in the classroom, taking as relevance the methodology, didactics and social skills. In the results obtained, most teachers have difficulties in the "Teacher/Student" relationship. It was possible to base an intervention so that learning occurs in a more humane way, strengthening the bond between teacher and student for the construction of knowledge, together with all the school actors.

KEYWORDS: Article. Humanization. School psychology.

\section{Introdução}

A formação de conhecimentos vai além do âmbito puramente metodológico e didático, sendo fundamental o reconhecimento de sua perspectiva humana, a principal função da escola deve ser com a humanização, pois conhecimentos, conteúdos estão disponíveis em diferentes formas, são encontrados com facilidade, mas é por meio das relações humanas que aprendemos a ser e a conviver, é necessário essa linha de pensamento internalizada, para favorecer uma formação mais humanizada.

As concepções do fracasso escolar até meados de 1970, em que a atuação em Psicologia nas escolas pautava-se em ações clínica, individualizadas, em que as falhas no processo de aprendizagem eram exclusivamente de responsabilidade do aluno e de seus familiares. Logo, por muitos anos a escola foi autorizada a se eximir da responsabilidade pelas dificuldades escolares, ignorando assim determinantes escolares, políticos e sociais das dificuldades de escolarização. Quando a família e a escola apresentam boas relações, o aprendizado e o desenvolvimento do aluno tornam-se maximizados; uma vez que o aluno percebe por parte de seus familiares confiança e valorização àquele contexto de aprendizado.

Para Freire (1996), o educador e o educando trocam de papéis sempre, o aluno aprende na medida em que o professor ensina e o professor ensina e aprende no contato com o aluno. 
Neste processo, ainda é necessário observar histórias e trajetórias dos discentes, que são únicas, reconhecendo que existem limitações em ambos, em suas esferas sociais, culturais, afetivas, entre outras. Diante disso, responsáveis e professores devem ser estimulados a buscarem estratégias conjuntas ao seu papel. A escola deve reconhecer a importância da colaboração dos pais na história e no projeto escolar dos alunos e, auxiliar as famílias a exercerem o seu papel na educação, na evolução e no sucesso profissional dos filhos e, concomitantemente, a transformação da sociedade.

Com base numa pesquisa de campo, com a utilização de questionários, foram realizados levantamentos de dados, tendo como objetivos identificar, intervir e realizar uma sensibilização que promova conhecimentos sobre a humanização, do ensino presentes na prática docente dos professores do ensino fundamental I. A intervenção foi realizada em uma Escola Municipal em uma cidade no interior do estado de São Paulo, com o intuito de ampliar a discussão que possibilite ao pedagogo refletir sobre o processo de ensino e aprendizagem dos alunos, diferenciando assim o ensino humanizador do não humanizador.

\section{Revisão de literatura}

\section{Contexto histórico}

Segundo Antunes (2008), historicamente nota-se que a psicologia brasileira, como área de conhecimento instituída, surgiu na primeira metade do século XIX, nos contextos educacionais, após a criação dos cursos de Medicina e Direito, o autor aponta que produção de um conhecimento psicológico acadêmico no país teve origem através dos médicos nas primeiras faculdades de Medicina do Brasil.

Numa perspectiva mais ampla Antunes (2008) ainda diz que:

A história da Psicologia Escolar e Educacional no Brasil pode ser identificada desde os tempos coloniais, quando preocupações com a educação e a pedagogia traziam em seu bojo elaborações sobre o fenômeno psicológico. No século XIX, ideias psicológicas articuladas à educação foram também produzidas no interior de outras áreas de conhecimento, embora de maneira mais institucionalizada. No campo da pedagogia, escolas normais (criadas a partir da década de 1830) foram espaços de discussão, ainda que incipientes e pouco sistemáticos, sobre a criança e seu processo educativo, incluindo temas como aprendizagem, desenvolvimento, ensino e outros. Em meados do século, essa preocupação torna-se mais sistemática e frequente e, nos anos finais desse mesmo século, é possível perceber a incorporação de conteúdos que mais tarde viriam a ser considerados como objetos próprios da psicologia educacional, com particular interesse por temas anteriormente estudados, como aprendizagem e desenvolvimento, mas também por outros que já seriam 
considerados expressões da psicologia do século XX, como a inteligência, por exemplo (ANTUNES, 2008, p. 469).

Para Antunes (2008) as ações em Psicologia na escola devem considerar a realidade escolar, dentro e fora dos muros da escola, as dimensões sociais, políticas, pessoais e institucionais. Diante disso, a Psicologia escolar tem muito que contribuir para a gestão escolar; de modo a considerar as interações presentes na escola: direção-professor, professor-professor, professor-aluno. A educação é constituída por múltiplos, determinantes, dentre os quais os fatores de ordem psicológica; portanto, a psicologia tem contribuição para a Educação.

Em 1890, o conhecimento psicológico já compunha o currículo das instituições formadoras de professores, as Escolas Normais. Segundo Antunes (2008) as práticas psicológicas presentes nessa época eram marcadas por objetivos adaptacionistas, corretivos e normativos, diante disso, os profissionais solicitados pela escola atuavam numa perspectiva diagnóstica, avaliativa e classificatória.

Surge então o movimento da Escola Nova, que contribuiu para a construção de um novo pensamento no interior da Psicologia como um todo e da Psicologia em sua relação com a Educação. Iniciava-se, então, um novo período para além da Psicologia normativa e classificatória, Antunes (2008) cita que os processos de escolarização começaram a ser entendidos de modo diferente, procurando compreender a gênese dos fenômenos e ampliar os olhares sobre o ensinar, o aprender e as práticas desenvolvidas no interior da Psicologia. Contudo, em 1980, o exemplo de atuação do psicólogo com foco no indivíduo e em práticas normativas já vinha sendo criticado pelos próprios profissionais de Psicologia, diante das novas percepções das dificuldades de aprendizagem.

Segundo Martinez (2009), os psicólogos escolares perceberam a necessidade de ampliar olhares, assumir riscos na defesa de questões sociais e políticas para o desenvolvimento de práticas mais contextualizadas e com foco na transformação social, deixando de ser um mero aplicador de testes e implementador de práticas individualizantes para se tornar um profissional crítico da realidade escolar e das demandas de aprendizagem.

\section{Por uma educação humanizada}

Humanização é um termo que faz referência a alguma prática que visa tornar algo ou alguém mais humano, a consequência de humanizar. Humanização pode ser usado nesse sentido sob vários aspectos, para Ferreira (1975), o termo humano vem do latim humanu, em que humanização seria o ato ou efeito de humanizar-se, que por sua vez significa tornar 
humano; tornar benévolo, civilizar. A humanização é um termo que surge no período renascentista no século $\mathrm{XV}$, com o movimento humanista.

A escola é um espaço no qual é preciso desenvolver atividades que fortaleçam o desenvolvimento das crianças e adolescentes que convivem diariamente neste local, contribuindo com a criação de ambientes saudáveis e o fortalecimento de estilos de vida saudáveis (VIEIRA; AERTS; CÂMARA; SCHUBERT; GEDRAT; ALVES, 2017, p. 917)

Antunes (2008) traz, um olhar sensível para essa realidade que vem se perdendo num processo histórico, por meio de contradições da sociedade, do sistema educacional, de representações sociais desencontradas que desencadeiam nos professores estranhamento no processo de conceber a prática pedagógica, insensibilidade na maneira de perceber os envolvidos, estabelecendo relações apáticas em que sobressai a indiferença, proporcionando aos mesmos, perdas na sua condição humana de ser. Para Antunes (2008) pensar humanização no cenário escolar possibilita refletir sobre as problemáticas enfrentadas pelo docente no desenvolvimento de suas atividades, nos dias atuais, são recorrentes observações de que o professor vem perdendo seu olhar humano diante da educação.

Segundo Jose et al. (2015), o professor, em seu fazer e pensar pedagógico, não está sozinho, mas inserido em um grupo e, é nesse grupo, que vai construir uma polissemia de sentidos, realizar uma ressignificação do que é produzido na inter-relação entre sujeitos.

Todos nós possuímos uma história e contá-la significa lembrar ou relembrar acontecimentos. Contá-la e ouvi-la é ter e oferecer a oportunidade de construir conhecimento. A vida precisa ser contada e ouvida. É dela, ou, são delas - das inúmeras vidas que conhecemos - que se retira o conteúdo da aprendizagem. (ROCHA; REIS, 2020, p. 885)

É nesse conjunto que se criam novas referências e se reescreve aquilo que é vivenciado. O professor tem sua perspectiva, mas também tem o olhar do grupo e assim ele vai dando forma ao objeto. Jean Piaget (1982) revela que há uma constante interação entre o indivíduo e o mundo exterior, sendo este o processo pelo qual se dá o desenvolvimento intelectual do ser humano. Esta interação estabelece uma constante oscilação entre o equilíbrio e o desequilíbrio promovendo desta forma a adaptação de novos saberes quando o equilíbrio se estabelece. A adaptação se dá quando ocorre a assimilação e acomodação de um novo saber, assim desde o nascimento, a criança é estimulada pelo mundo externo e desafiada a experimentar as mais diferentes sensações e situações, e assim vai adquirindo novas estruturas de pensamento.

Vygotsky (1994) tem como base o caráter social da aprendizagem, destacando o papel das relações sociais, o mesmo autor defende que é através da interação com outros que a criança 
incorpora os instrumentos culturais. Ao destacar a importância das interações sociais, traz a ideia de mediação e da internalização como aspectos fundamentais para a aprendizagem, defendendo que a construção do conhecimento ocorre a partir de um intenso processo de interação entre as pessoas. Nesse sentido, Vygotsky destaca a importância do outro não só no processo de construção do conhecimento, mas também de constituição do próprio sujeito e de sua maneira de agir. Segundo o autor, o processo de internalização envolve uma série de transformações que colocam em relação ao social e o individual, afirmando que "Todas as funções no desenvolvimento da criança aparecem duas vezes: primeiro, no nível social, e, depois no nível individual; primeiro entre pessoas (interpsicológica), e, depois, no interior da criança (intrapsicológica)" (VYGOTSKY, 1994, p. 75).

Antunes (2008) entende a educação como prática social humanizadora, intencional, cuja finalidade é transmitir a cultura construída historicamente pela humanidade. Nessa perspectiva histórico-cultural, o conceito de humanização, "significa compreender que o homem não nasce humano, ou seja, que os fatores que carrega consigo, herdados geneticamente e que a natureza lhe provê são importantes, porém, não suficientes para que se torne humano" (JOSE et al., 2015, p. 5120).

Para o conceito de humanização, segundo Jose et al. (2015), o indivíduo precisa se apropriar da cultura humana herdada das gerações passadas, por meio da relação com outros seres humanos, de forma a desenvolver seu potencial, sua inteligência e sua personalidade.

Nas relações presentes no ambiente escolar, encontram-se as relações família, escola e comunidade, para Goleman (1996) a família que, reunida a outros segmentos da sociedade, forma a grande teia social, proporciona à criança a estrutura de um caráter positivo ou não. São grandes os desafios de se estabelecer e/ou fortalecer a parceria entre a família e a escola. Muitas vezes, a família é vista como a culpada das dificuldades apresentadas pelos alunos em sala de aula, o que dificulta ainda mais a parceria necessária. A família é nossa primeira escola emocional, que esse aprendizado emocional atua não apenas por meio das coisas que os pais fazem ou dizem diretamente às crianças, mas também nos modelos que oferecem para lidar com os próprios sentimentos, para o autor, alguns pais são professores emocionais talentosos, outros atrozes.

Para o processo de aprendizagem, a figura do professor é de suma importância, Jose et al. (2015) asseguram que as ações dos professores são necessárias ao processo de aprendizagem, de modo que o professor deve estar atento às exigências da tarefa e às habilidades de todos os seus alunos. As atividades propostas em sala de aula precisam ser planejadas para contemplar um conjunto amplo de capacidades, evitando centrar-se 
exclusivamente nas habilidades acadêmicas convencionais, possibilitando, assim, o engajamento e participação de todos os alunos em sala de aula. A escola deve oferecer uma diversidade de experiências, tanto culturais quanto sociais, para isso o professor precisa mediar o processo de humanização dos alunos.

A relação professor-aluno deve ser efetiva e promotora de desenvolvimento ao aluno, compreendida, portanto, como interatividade, cujas ações de alunos e professores são conjuntas no processo de aprender. Jose el al. (2015), traz que o professor deve ser incentivado a favorecer a autonomia dos alunos e motivá-los no engajamento das atividades, implementar atividades cooperativas e auxiliá-los no desenvolvimento social, afetivo e cognitivo. Além disso, ele deve se comprometer com a qualidade da educação e sua proposta de transformação social, pois é no período da infância que a criança aprende as qualidades humanas naturais, ou seja, é nesse processo que se desenvolve sua inteligência e personalidade.

Barasoul (2016) cita que para se obter uma comunicação mais humanizada no processo educacional será preciso que o docente crie um novo olhar sobre a forma de ver o outro, de uma maneira menos individual, mas sim mais social. Diante de tantas transformações sociais, culturais, o avanço das tecnologias coloca em evidencia novas responsabilidades e possibilidades de intervenção social, a partir de novas práticas educativas que compreendam os educadores, tendo como objetivo uma educação mais humanizada.

Segundo Wiebusch (2012) Paulo Freire trabalha com a concretude da produção do sentido e do sentir amorosidade/amor como uma potencialidade e uma capacidade humana que remete a uma condição de finalidade existencial ético-cultural no mundo e com o mundo. Uma amorosidade partilhada que proporcione dignidade coletiva e utópicas esperanças em que a vida é referência para viver com justiça neste mundo. A amorosidade Freireana percorre toda sua obra e sua vida se materializa no afeto como compromisso com o outro, que se faz engravidado da solidariedade e da humildade. Usando o prefixo com, ganha força a ideia de compromisso que pode significar prometer-se consigo e com o outro.

Freire (2005) enfatizou a necessidade de a educação ser uma prática humanizadora, para ele, a humanização é sempre um processo que passa pela ruptura das amarras reais de ordem econômica, política, social, ideológica, que nos estão condenando a desumanização.

Segundo Barasuol (2016) para que essa forma de educar aconteça é de fundamental importância que ocorra uma transformação, segundo o autor, para que se trabalhe em grupo de maneira efetiva, os alunos devem contar com outras capacidades que necessitam ser incentivadas pelo contexto escolar geral, tais como: habilidades comunicativas, planejamento e desenvolvimento de tarefas, autorregulação, habilidade de resolver problema, respeito e ajuda 
mútua, para o autor educar é dar esperança, é proporcionar uma transformação na vida dos estudantes. $\mathrm{O}$ educador precisa ter a percepção sobre um todo do aluno. Nesse sentido, a educação requer intensamente a força de um olhar com o coração.

Para Vygotsky (1994) o papel do professor no processo de aprendizagem torna-se fundamental, logo, a mediação e a qualidade das interações sociais ganham destaque. O afeto é um ato indispensável para boas relações humanas, eficaz para reforçar potencialidades podendo ser entendido como a energia necessária para a estrutura cognitiva passe a operar.

\section{Objetivo}

O objetivo deste artigo foi estudar as dificuldades de aprendizagem encontradas pelos docentes, tendo como objetivos identificar, intervir e realizar uma sensibilização com intuito de promover os conhecimentos sobre a humanização do ensino presentes na prática docente.

\section{Metodologia}

\section{Participantes}

Participaram do presente trabalho os docentes envolvidos no contexto educacional de uma escola municipal de ensino fundamental da cidade de Lençóis Paulista no interior de São Paulo. Essa comunidade escolar, onde o estágio foi realizado durante 3 meses, tem cerca de 16 docentes.

\section{Instrumentos}

Foram utilizados como instrumentos para coleta de dados: questionário auto aplicado, contendo questões abertas e fechadas para levantamento das dificuldades e recursos específicos dos docentes de forma a embasar e adequar a sequência dos temas no módulo de intervenção. As questões do questionário foram analisadas a partir das repostas dos professores sobre sua visão diante da metodologia e prática docente. Elementos para análise foram obtidos a partir de 2 questionários diante da vivencia dos professores com seus alunos até ali.

\section{Procedimentos}

A pesquisa teve como fundamento a abordagem qualitativa que, segundo Grubits (2004), postula a existência de um veículo dinâmico e indissociável entre o mundo objetivo e a 
subjetividade do sujeito, referindo-se a uma multiplicidade de métodos de investigação. Primeiramente, observou-se sistematicamente a escola para detectar as demandas, o funcionamento e relações que lá se estabeleciam entre seus membros. A partir de observações e conversas informais com os docentes, percebeu-se a necessidade de uma intervenção junto aos professores para que estes pudessem falar a respeito de suas necessidades e dificuldades relativas às relações interpessoais, ao ser professor e, principalmente, à relação professor/aluno. A partir disso, foram propostas "reuniões em grupo", com o intuito de discutir a respeito das dificuldades em relação às demandas observadas. Essas reuniões ocorreram em dois turnos, possibilitando que todos os professores pudessem participar. Os professores eram convidados a participar e, caso viessem, estavam assentindo participar da intervenção. Posteriormente, foram discutidas formas de melhorar situações e problemas que bloqueavam o vínculo aluno/professor.

Foram realizadas duas reuniões em grupo na modalidade participativa, as quais abordaram o tema relativo à seguinte demanda: relação professor/aluno.

Dessa forma, investiu-se na explanação oral com os professores, com objetivo de estreitar a necessidade do vínculo entre professor e aluno para a construção do conhecimento, juntamente com todos os atores da escola.

\section{Resultados}

Quanto a inserção de um estagiário de psicologia escolar nessa instituição, a equipe diretiva foi receptiva e demonstrou interesse no trabalho em conjunto com a Psicologia. Os professores, de maneira geral, também demonstraram boa aceitação, ainda que tenha havido um receio inicial. Os resultados aqui descritos e discutidos abordam especificamente algumas intervenções com os professores.

Além das dificuldades explicitadas pelos professores em geral, observou-se grande dificuldade de relacionamento dos profissionais com os alunos, no que diz respeito a "relações interpessoais", incluindo a temática "relação Professor/aluno". Percebeu-se ainda que havia um sentimento de impotência por parte dos professores ao lidar com tais questões, sendo que muitos deles afirmaram precisar de um espaço para dialogar.

Foi proposto que se formassem duas reuniões em grupo, onde elas pudessem ter um espaço para falar sobre os problemas que relataram em diferentes ocasiões, sobre a profissão, sobre o que as incomodava. Algumas professoras falaram que não gostam de falar sobre isso em grupo e que não conseguem se abrir. Mesmo assim, a proposta ficou em aberto. Foi cedido 
o espaço das reuniões pedagógicas para as duas primeiras reuniões, com o tema: Relação Professor/aluno, a qual foi realizada com professores da etapa 1 e 2 e alguns professores do fundamental 1, pelo turno da manhã. Os professores do turno da tarde foram convidados, mas nenhum compareceu.

Foram discutidos três processos importantes que ocorrem na interação professor/aluno: vínculo afetivo, introjeção, projeção e adaptação.

Uma das funções do vínculo é exatamente dar a sensação de proteção e conforto para a criança, cujo primeiro impulso é transferir para o professor a relação de segurança que teria com a mãe. Darido e Bizelli (2015, p. 62), "há que se quebrar o paradigma educacional, promovendo aprendizagem ao invés de ensino, saindo da pedagogia instrucionista para a construcionista: o educando tem que construir seu conhecimento “.

Nesse momento, o educador é o mediador afetivo da criança nesse espaço escolar, e quem facilita sua adaptação. Na introjeção, a criança interioriza imagens dos pais ou adultos que desempenham esses papéis, o que passa a constituir uma parte de sua personalidade, na projeção, o indivíduo lança em outros as características (na maioria das vezes indesejáveis) de que é incapaz de perceber em si mesmo. Alguns professores começaram a dar exemplos de sala de aula, de como possuem antipatias com alguns alunos e se perguntam o porquê, muitas vezes não sabendo encontrar motivos que as justifiquem. Já outros professores não concordaram com os referidos mecanismos de interação, justificando apenas que era difícil estar em situação de sala de aula e conviver diariamente com alunos. Explicou-se que se costuma evitar o contato com as pessoas e alunos por quem se tem antipatias, esses não têm a possibilidade de exibir qualidades que poderíamos vir a admirar.

Diante da pergunta sobre como poderiam fazer para que o ciclo de antipatia pudesse cessar, o estagiário de psicologia trouxe que era possível buscar, em cada aluno, as qualidades desejáveis em vez de acentuar sua inadequação para determinadas tarefas. Por isso a importância de investir nos potenciais e qualidades de cada aluno e não apontar defeitos, tendo assim como objetivo ter uma educação mais humanizadora.

Os professores, por meio das reuniões em grupo desenvolvidas, passaram a apresentar uma postura diferenciada em relação às questões de afeto e cognição. A dimensão afetiva passou a ocupar lugar de destaque para muitos docentes. 


\section{Discussão}

Com base em uma perspectiva histórico-cultural, a teoria de Wallon destaca-se nos estudos sobre afetividade, afirmando em sua teoria da Psicogênese da Pessoa Completa, que a dimensão afetiva, ao longo de todo o desenvolvimento do indivíduo, tem um papel fundamental para a construção da pessoa e do conhecimento. Muitos professores que atuam nas escolas não se dão conta da importante dimensão que tem o seu papel na vida dos alunos, nesse sentido, um dos aspectos que se quer ressaltar é a importância da formação do professor e da compreensão que ele deve ter em relação a esse assunto. Pois, não há como acontecer na escola uma educação adequada às necessidades dos alunos sem contar com o comprometimento ativo do professor na totalidade do aluno. Segundo Wallon (2007), o termo afetividade corresponde às primeiras expressões de sofrimento e de prazer que a criança experimenta, sendo essas manifestações de tonalidades afetivas ainda em estágio primitivo, ou seja, de base orgânica e têm por fundamento o tônus. Este, por sua vez, representa a base de onde sucedem as reações afetivas e mantem uma relação estreita com a afetividade durante o processo de desenvolvimento humano. Ao se desenvolver, a afetividade passa a ser fortemente influenciada pela ação do meio social. Wallon (2007) defende uma evolução progressiva da afetividade, cujas manifestações vão se distanciando da base orgânica, tornando-se cada vez mais relacionadas ao social. Wallon (2007) cita que as interrelações entre fatores orgânicos e sociais e condições históricas e culturais possibilitam e limitam o desenvolvimento da criança, ao ressaltar a necessidade de estudar a criança na sua totalidade.

Vygotsky (1994) destaca a importância do outro não só no processo de construção do conhecimento, mas também de constituição do próprio sujeito e de sua maneira de agir. Segundo o autor, o processo de internalização (momento em que a criança aprende por meio da relação com outro indivíduo) envolve uma série de transformações que colocam em relação ao social e o individual, para Vygotsky (1994) o professor é um mediador das potencialidades da criança. Piaget (1982) cita que há uma constante interação entre o indivíduo e o mundo exterior, sendo este, o processo pelo qual se dá o desenvolvimento intelectual do ser humano. Esta interação estabelece uma constante oscilação entre o equilíbrio e o desequilíbrio promovendo desta forma a adaptação de novos saberes quando o equilíbrio se estabelece.

A educação freireana está diretamente associada, interligada ao conceito de ser humano. Segundo Freire (1997) a educação é uma prática antropológica, atesta também que para pensar refletir a respeito da educação há que se, concomitantemente pensar, refletir sobre o ser 
humano, pois nele reside o fundamento do processo educativo. O ser humano para Freire (1997) é um ser inacabado e, consciente disso, aspira "Ser Mais".

Já para Freud (1996), ao longo do processo de amadurecimento, a criança desenvolve a necessidade de estabelecer um vínculo com a mãe ou um cuidador substituto. Tanto a estrutura psíquica como o sistema biológico da criança estão em desenvolvimento. Devido à ausência da capacidade de provimento das próprias necessidades básicas, é necessário que surja o apoio responsivo de alguém para contribuir com o desenvolvimento do infante. Freud $(1921 ; 1996)$ traz o vínculo afetivo como uma forma de se relacionar com o outro na perspectiva de manterse ligado emocional e/ou comportamentalmente, apresenta-se na relação cuidador e criança como um meio de subsistência e manutenção de um ambiente adequado para o desenvolvimento maturacional sadio desta última. A proximidade de ambos funciona como uma busca pela segurança e apoio, quer seja nos momentos de adversidade, quer seja para proporcionar uma capacidade funcional da personalidade da criança.

Ademais Freud (1996) resume esse processo, dizendo que:

[...] Primeiro, a identificação constitui a forma original de laço emocional com um objeto; segundo, de maneira regressiva, ela se torna sucedâneo para uma vinculação de objeto libidinal, por assim dizer, por meio de introjeção do objeto no ego; e, terceiro, pode surgir com qualquer nova percepção de uma qualidade comum partilhada com alguma outra pessoa que não é objeto de instinto sexual. Quanto mais importante essa qualidade comum é, mais bem sucedida pode tornar-se essa identificação parcial, podendo representar assim o início de um novo laço (FREUD, 1996, p. 117).

\section{Conclusão}

Este artigo, através da experiência em psicologia escolar, possibilitou as possíveis intervenções que esse profissional pode executar enquanto agente de mudanças no interior da escola, sobretudo quando se trata de um trabalho de inserção e construção do lugar de psicólogo. Não foi intenção deste estudo engessar as práticas, mas revelar como pequenas intervenções podem produzir mudanças no contexto escolar ampliado. Dessa forma, é possível que o profissional de psicologia escolar possa ter foco na escola como um todo, apesar das dificuldades ainda presentes no cotidiano de atuação desse profissional. É importante considerar que, como em toda a pesquisa, esta revelou apenas alguns aspectos delimitados pela temática, pois a relação professor-aluno, vai muito além das questões aqui analisadas, isso acontece principalmente, devido às constantes e aceleradas mudanças que ocorrem na sociedade e são refletidas no contexto escolar. 
O ponto de partida dessa proposta teve início com uma questão bastante relevante e que preocupa muito todas as pessoas que fazem parte dos ambientes escolares: a relação professoraluno e o processo ensino-aprendizagem. Foram visíveis as mudanças a partir dos resultados obtidos e alguns pontos merecem destaque. Os professores sentiram-se estimulados e convidados a dar continuidade nos momentos de estudo e reflexão em conjunto, A percepção sobre o aluno se modificou. Agora os professores apresentam uma visão mais compreensiva e positiva desses sujeitos. A dimensão afetiva passou a ocupar lugar de destaque para muitos docentes. Quando todos estão unidos por uma causa, os problemas podem ser minimizados e isso é possível.

\section{REFERENCIAS}

ANTUNES, M. A. M. Psicologia Escolar e Educacional: história, compromissos e perspectivas. Psicol. Esc. Educ., Campinas, v. 12, n. 2, p. 469-475, dez. 2008. Disponível em: http://www.scielo.br/scielo.php?script=sci arttext\&pid=S1413-85572008000200020. Acesso em: 16 out. 2019.

BARASUOL, V. S. A Comunicação humanizadora no processo da educação. In: SEMINÁRIO INTERINSTITUCIONAL DE ENSINO, PESQUISA E EXTENSÃO, 21., 2016, Cruz Alta. Anais [...]. Cruz Alta: Universidade de Cruz Alta, 2016. Disponível em: https://docplayer.com.br/114160020-A-comunicacao-humanizadora-no-processo-daeducacao.html. Acesso em: 12 nov. 2019.

DARIDO, M. C.; BIZELLI, J. L.Inovações tecnológicas e contexto escolar: reflexões necessárias. Revista Ibero-Americana de Estudos em Educação, p. 50-66, 2015. ISSN 1982-5587. Disponível em:

https://periodicos.fclar.unesp.br/iberoamericana/article/view/7772. Acesso em: 20 jul. 2020. DOI: https://doi.org/10.21723/riaee.v10i1.7772.

FERREIRA, A. B. H. Novo dicionário aurélio. Rio de Janeiro: Nova Fronteira, 1975.

FREUD, S. Psicologia de grupo e análise do ego. Rio de Janeiro: Imago, 1996.

FREIRE, Paulo. Pedagogia da autonomia: saberes necessários à prática educativa. São Paulo: Paz e Terra, 1996.

FREIRE, P. Educação como prática da liberdade. 1997. Disponível em: https://cpers.com.br/wp-content/uploads/2019/09/5.-Educa\%C3\%A7\%C3\%A3o-comoPr\%C3\%A1tica-da-Liberdade.pdf. Acesso em: 08 out. 2019.

FREIRE, P. Pedagogia do oprimido. 40. ed. Rio de Janeiro: Paz e Terra, 2005.

GOLEMAN, D. Inteligência emocional. 2 ed. Rio de Janeiro: Objetiva, 1996. 
GRUBITS, S. et al. Método qualitativo: epistemologia, complementaridades e campos de aplicação. São Paulo: Vetor, 2004.

JOSE, L. S. C.; STEFFEN, D. N.; BARROS, F. C. O. M. Teoria e prática na formação de professores: por uma educação humanizadora. In: CONGRESSO NACIONAL DE EDUCAÇÃO - EDUCERE, 12., 2015, Curitiba. Anais [...]. Curitiba: Pontifícia Universidade Católica do Paraná, p. 5120-5130, 2015. Disponível em:

https://educere.bruc.com.br/arquivo/pdf2015/18831_7806.pdf. Acesso em: 13 out. 2019.

MARTINEZ, A. M. Psicologia escolar e educacional: compromissos com a educação brasileira. Psicol. esc. educ., Campinas, v. 13, n. 1, p. 169-177, jun. 2009. Disponível em: http://pepsic.bvsalud.org/scielo.php?script=sci_arttext\&pid=S1413-85572009000100020 Acesso em 14 out. 2019.

PIAGET, J. Psicologia e pedagogia. Rio de Janeiro: Forense Universitária, 1982. Psychologie et Pédagogie, 1969.

ROCHA, L. P.; REIS, M. B. F. A pesquisa narrativa em educação especial. Revista IberoAmericana de Estudos em Educação, Araraquara, v. 15, n. esp. 1, p. 884-899, maio 2020. eISSN: 1982-5587. DOI: https://doi.org/10.21723/riaee.v15iesp.1.13500

SANTANA, A. P. O.; DONIDA, L. O.; MONTEIRO, A. L. C. P.; SILVA, S. M.

Acessibilidade e permanência: um estudo do programa institucional de apoio aos estudantes da Universidade Federal de Santa Catarina. Revista Ibero-Americana de Estudos em Educação, p. 673-690, ago. 2015. E- ISSN 1982-5587. Disponível em: https://periodicos.fclar.unesp.br/iberoamericana/article/view/7919. Acesso em: 20 jul. 2020. doi: https://doi.org/10.21723/riaee.v10i5.7919.

VIEIRA, A. G.; AERTS, D. R. G. C.; CÂMARA, S.; SCHUBERT, C.; GEDRAT, D. C.; ALVES, G. G. A escola enquanto espaço produtor da saúde de seus alunos. Revista IberoAmericana de Estudos em Educação, Araraquara, v. 12, n. 2, p. 916-932, 2017. Disponível em: http://dx.doi.org/10.21723/riaee.v12.n2.8492. E-ISSN: 1982-5587.

VYGOTSKY, L. S. A formação social da mente. São Paulo: Martins Fontes, 1994.

WALLON, H. A evolução psicológica da criança. Martins, 208 p., 2007.

WIEBUSCH, E. M. Escola: espaço de humanização. s/d. Disponível em:

https://www2.faccat.br/portal/sites/default/files/wiebusch.pdf. Acesso em: 11 nov. 2019.

ZITKOSKI, J. J. (Org.). Dicionário Paulo Freire. 2. ed. Belo Horizonte: Autêntica, 2010. 


\section{Como referenciar este artigo}

MEDOLAGO, J. L.; RODRIGUES, T. M. P.; MARIANO, M. L. Psicologia Escolar: humanizar é preciso. Doxa: Rev. Bras. Psico. e Educ., Araraquara, v. 22, n. 1, p. 137-151, jan./jun., 2020. e-ISSN: 2594-8385. DOI: https://doi.org/10.30715/doxa.v22i1.13975

Submetido em: 20/03/2020

Revisões requeridas em: 30/04/2020

Aceito em: 30/05/2020

Publicado em: 01/06/2020 